\title{
Zeven no-kostuumstukken uit de collectie van het Okura Museum of Art, Tokyo
}


Cat. I Gevoerde kariginu met wielmotief, zijde en goudfolie, Japan, 1700-1800, Okura Museum of Art, inv.nr. some 75

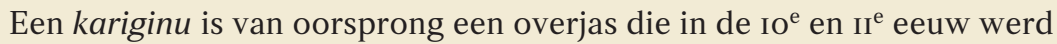
gedragen door hovelingen bij de jacht. Later werd het de meest formele dracht voor de samurai-elite. Het heeft een karakteristieke zijsluiting bij de gevoerde kraag en geregen draden bij de mouwopeningen. Vanaf de $I^{\mathrm{e}}$ eeuw werden ze ook speciaal voor het no-theater gemaakt. De stijl van versieren, met de krachtige, uitvergrote vormen, is wat flamboyanter dan gebruikelijk bij no-kostuums. Ze vormen hiermee een uitzondering en laten zien dat zelfs de gereguleerde, ingetogen no niet helemaal vrij bleef van invloeden vanuit het immens populaire kabuki-theater met zijn uitzinnige kostumering.

Op een diepgroene achtergrond zijn in goudfolie wielmotieven aangebracht. Dit van oorsprong Indiase motief is een symbool van bescherming van de boeddhistische wet. Op no-kledingstukken staat het motief voor het beschikken over buitengewone krachten en de kariginu wordt gedragen door personages die een jonge mannelijke godheid of een tengu (vogelachtige wezens die bekend staan om hun vechtkunsten) voorstellen. De weelderige versiering met de scherp afgetekende gouden motieven versterkt de indruk van de grote kracht van het personage. 


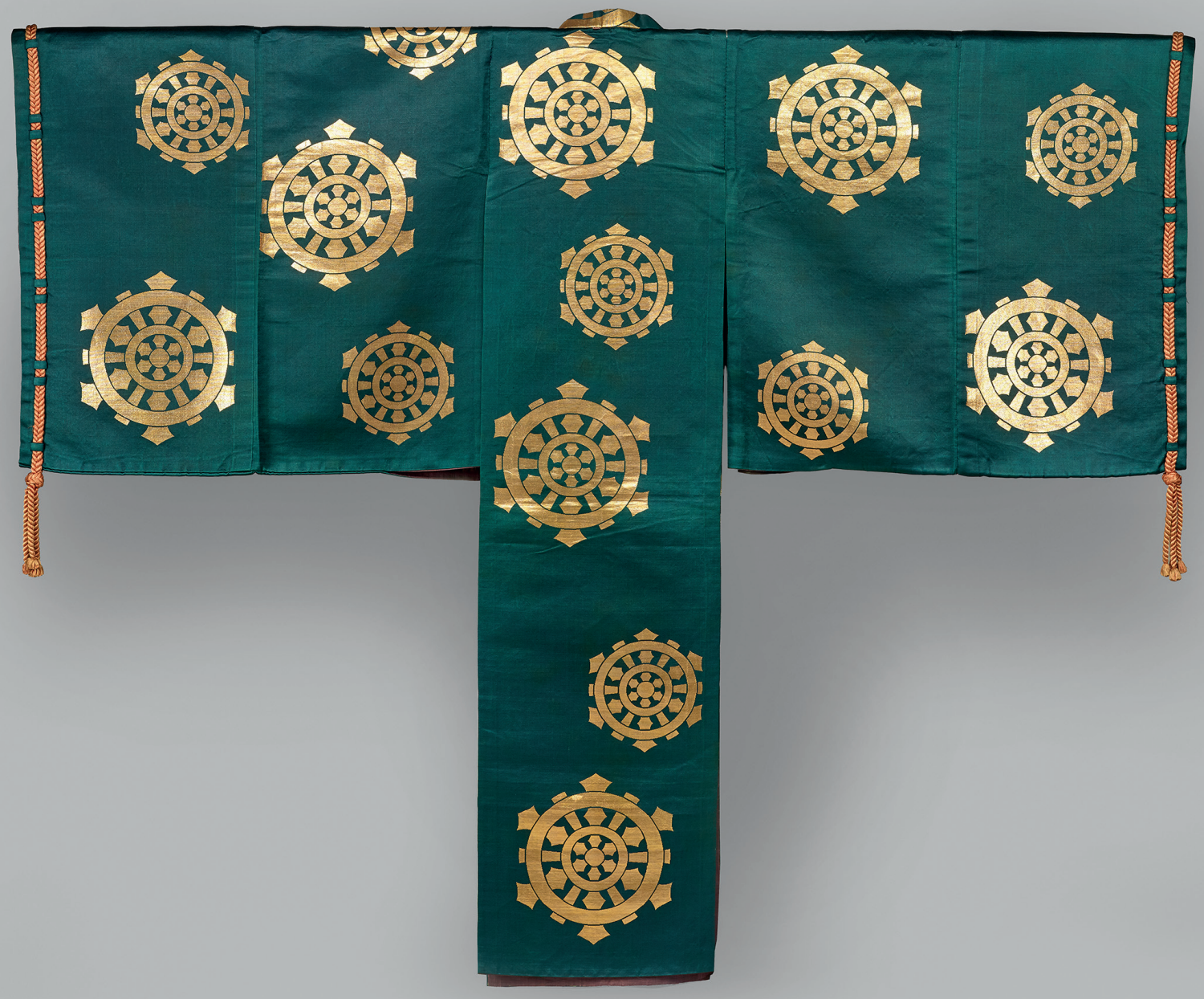




\section{Cat. 2 Hangiri met draak en wolkenmotieven, zijde en gouddraad,} Japan, 1800-1900, Okura Museum of Art, inv.nr. some 98

Een hangiri is een speciaal voor het no-theater ontwikkelde broekrok, gemaakt van goudbrokaat met grote motieven die zich over het hele kledingstuk uitstrekken, in dit geval twee draken. De in witte teensokken gestoken voeten van de acteur steken er onderuit en geven het geheel een meer actief uiterlijk.

Afb. 2

Tsukioka Kogyo,

Acteur in de rol van

Kasuga, de draak god, met wilde rode pruik en hoofdtooi in de vorm van een draak, kleurenhoutsnede, Japans papier, $378 \times 255$ mm., Japan, 1925, Rijksmuseum Amsterdam, inv.nr. RP-P-2003-275

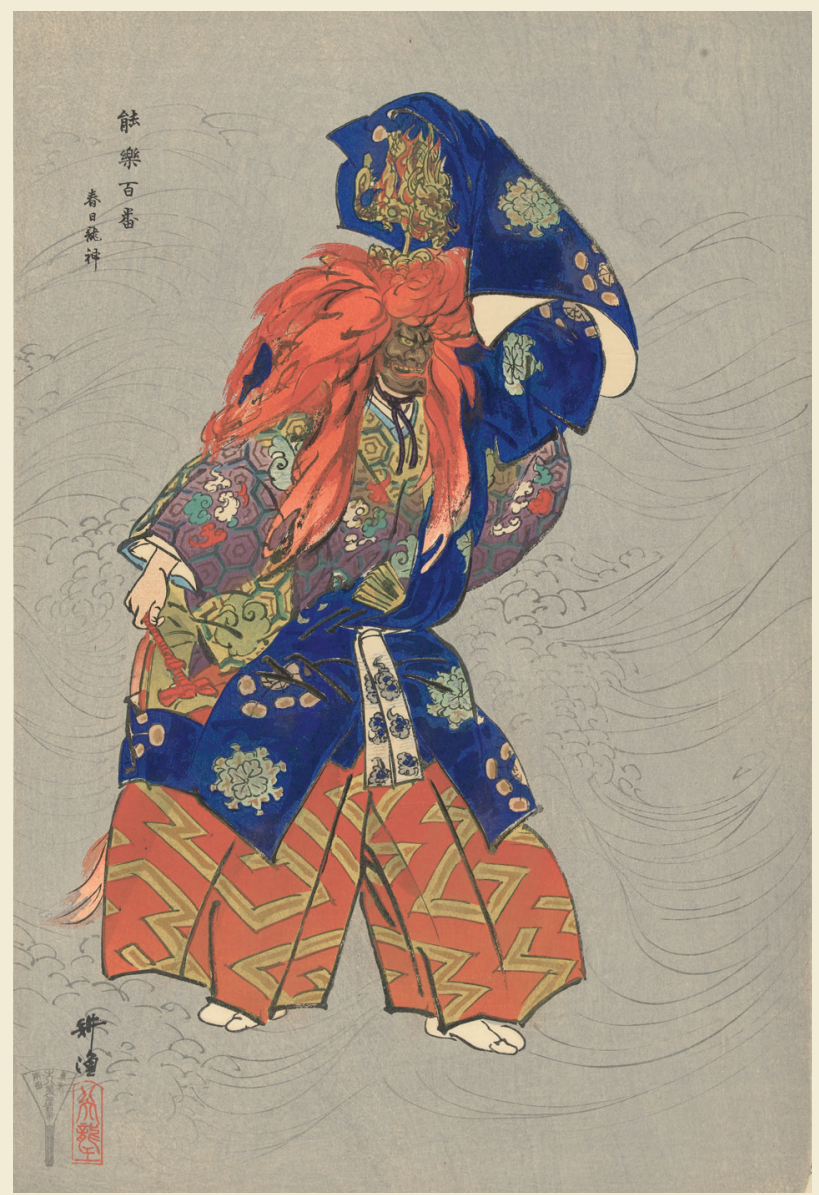




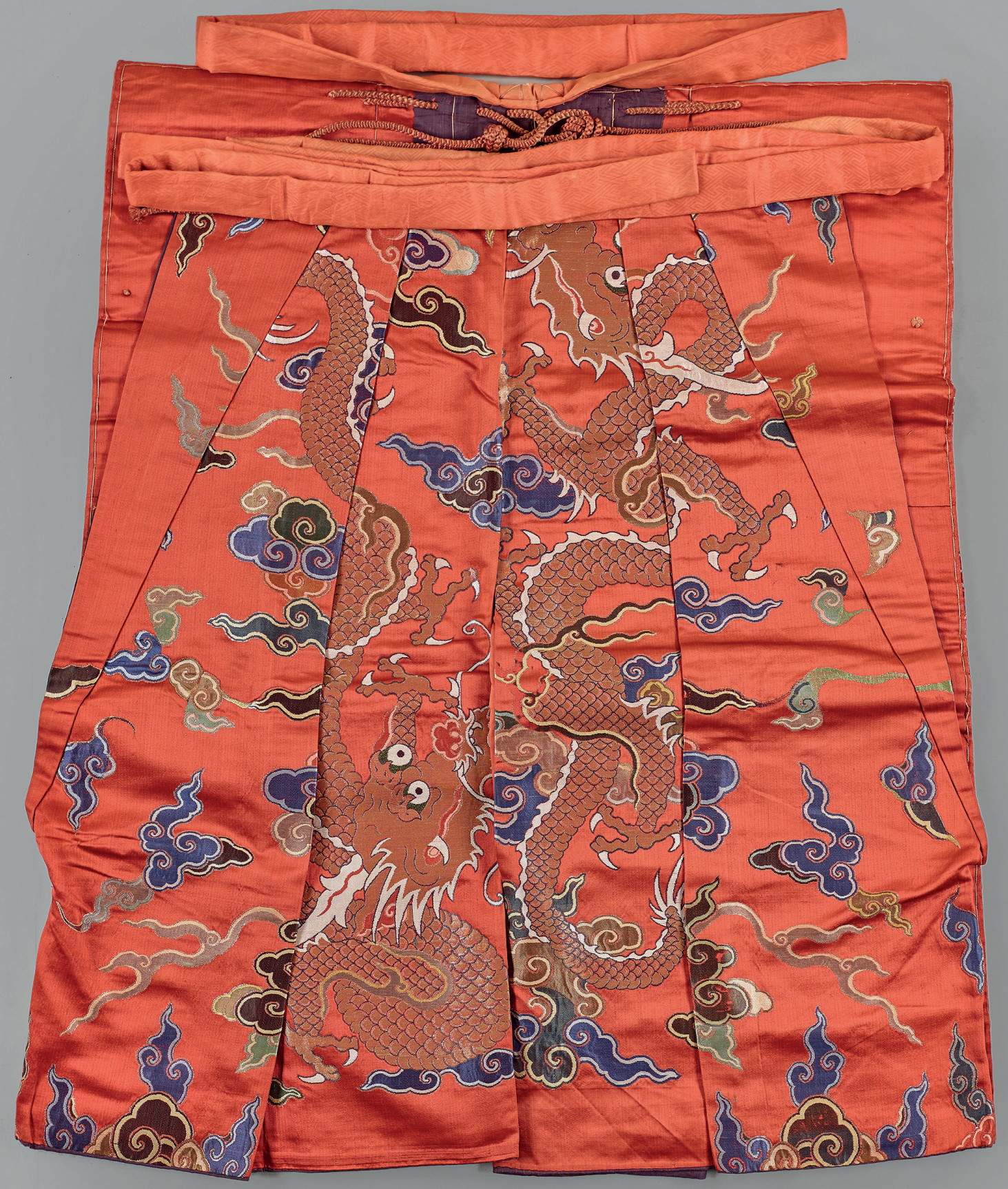


Cat. 3 Nuihaku met maanbloemen en takkenbossen, zijde en zilverfolie, Japan, 1700-1800, Okura Museum of Art, inv.nr. some 56

De versiering beweegt zich met een groot gebaar vanaf de linkerschouder naar rechts beneden, in de dramatische stijl die in het midden van de $i 7^{\mathrm{e}}$ eeuw geliefd was. De bloemranken zijn geborduurd op een saffraankleurige, damast gewoven zijde.

De witte maanbloem (yugao, Ipomoea alba) brengt de associatie met zich mee van Het verhaal van Genji, de vroeg $\mathrm{II}^{\mathrm{e}}$-eeuwse roman over de belevenissen van Prins Genji. In het vierde hoofdstuk, wordt de dan pas I7-jarige Genji halsoverkop verliefd op een onbekende, mysterieuze jonge vrouw die verblijft in een woning waar maanbloemen zich over de houten tuinmuur slingeren. Genji overtuigt haar om voor een nacht met hem te ontsnappen naar een verlaten, verwaarloosde villa. Het avontuur loopt dramatisch af. De geest van een door Genji verwaarloosde minnares verschijnt en neemt het leven van de mysterieuze jonge vrouw. Genji blijft ontroostbaar achter. Deze motieven van fragiele schoonheid, kwellingen door gevoelens en bovennatuurlijke elementen sluiten goed aan bij de thematiek van het no-theater. De episode inspireerde Zeami tot het schrijven van het no-stuk Yugao, waarin de geest van de gestorven jonge vrouw uiteindelijk verlossing vindt door de kracht van de Lotus Soetra. 


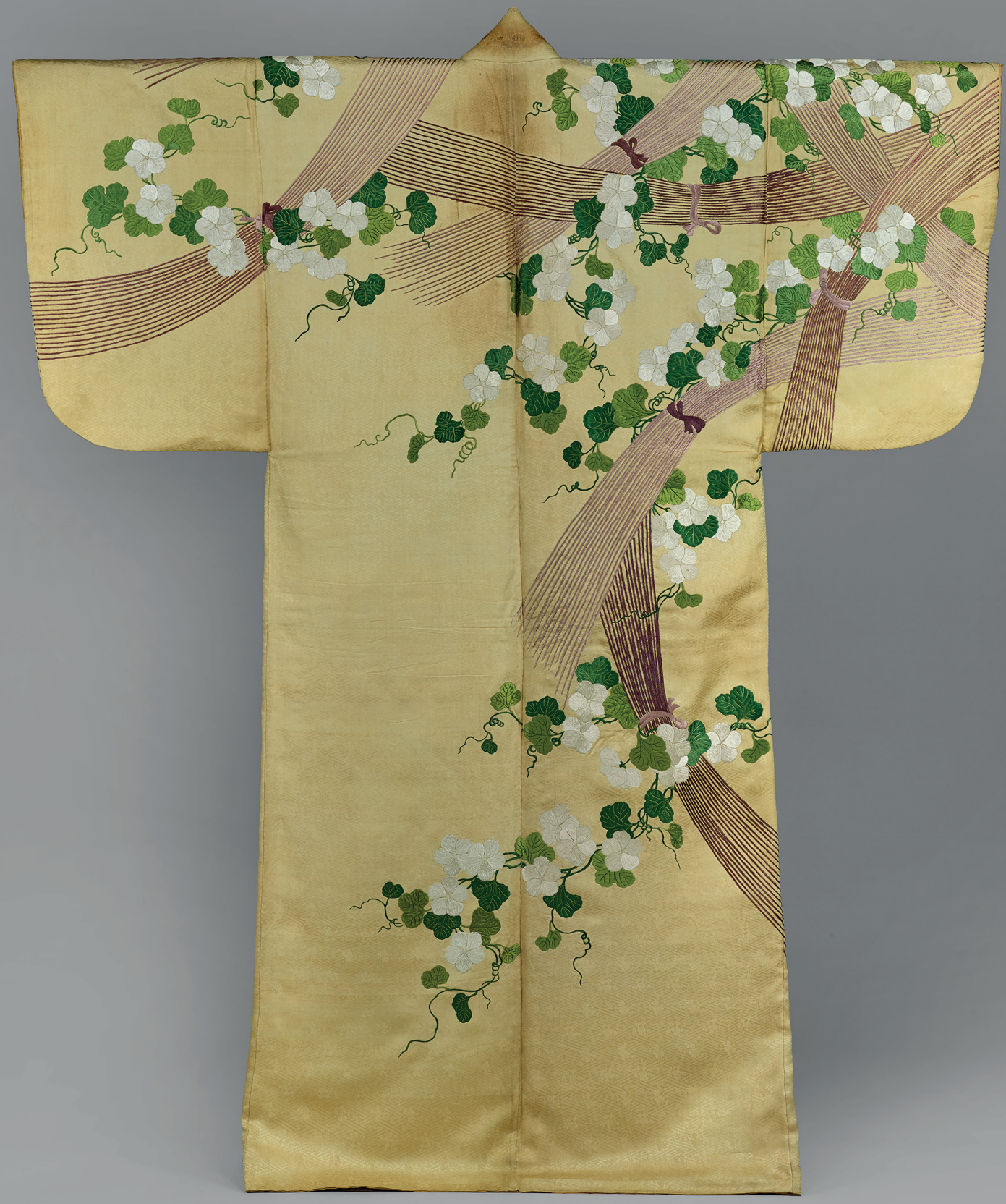


Cat. 4 Nuihaku met hekwerk en esdoornbladeren, zijde en zilverfolie, Japan, 1700-1800, Okura Museum of Art, inv.nr. some 57

De in de herfst helderrood verkleurende esdoornbladeren zijn groot en wat gestileerd weergegeven, in een eenvoudige maar markante vlakverdeling. Dit type kostuum wordt nuihaku genoemd, verwijzend naar de kenmerkende combinatie van borduurwerk (nui) en metaalfolie (haku) dat met lijm op de stof wordt gewreven.

Nuihaku kwam op in de $\mathrm{I}^{\mathrm{e}}$ eeuw voor vrouwenkleding en was destijds de meest luxueuze soort kimono. De nuihaku fungeerde toen als buitenste kledingstuk in het no-theater en in die tijd bedekten geborduurde patronen vrijwel het hele oppervlak. Toen in de $17^{\mathrm{e}}$ eeuw de gecompliceerde karaori-stoffen in zwang kwamen (zie cat. 5 en 6) verdrongen die nuihaku als rijkst-versierde stof. Vanaf die tijd werd een nuihaku-kostuum gedragen als tussenlaag en kon de versiering wat minder uitbundig zijn, zodat er een contrast ontstond met de overdadig versierde karaori-stof van het kledingstuk dat er overheen kwam. 


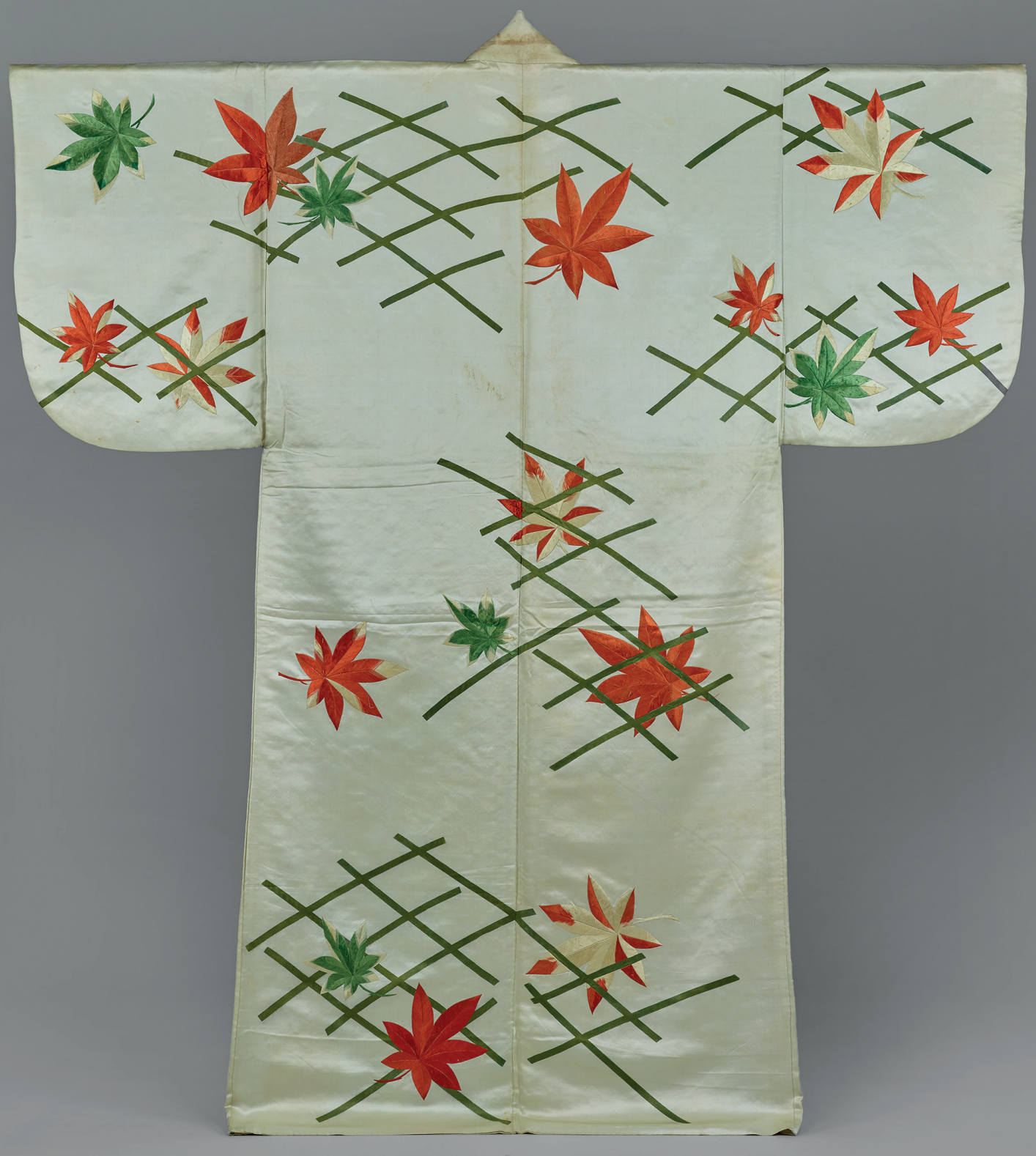


Cat. 5 Karaori met hoo en pioenroos, zijde en gouddraad, Japan, 1800-1900, Okura Museum of Art, inv.nr. some 8

Karaori (en nuihaku) worden ingedeeld in exemplaren met en zonder de kleur rood. Kostuums met rood als deze zijn voorbehouden aan rollen die jonge edelvrouwen verbeelden. De mythische vogels (hoo) en pioenrozen zijn beide gelukbrengende symbolen. Ze steken met hun heldere kleuren af tegen de al even kleurrijke achtergrond van een goud en rood blokpatroon, geweven op een gecompliceerde manier van de karaoritechniek. Daarbij wordt de hele versiering gemaakt met horizontale inslagdraden van geglansde zijde en met goudfolie bedekt plat draad. Het gouddraad is op de onderliggende stof gebonden, maar de kleurige draden van de motieven alleen aan de begin- en eindpunten. Daartussen lopen de draden los over de stof, zodat het net lijkt alsof de decoratie geborduurd is. 

Fis

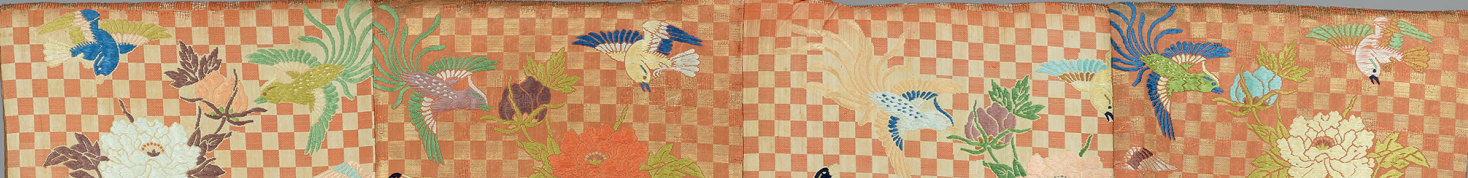

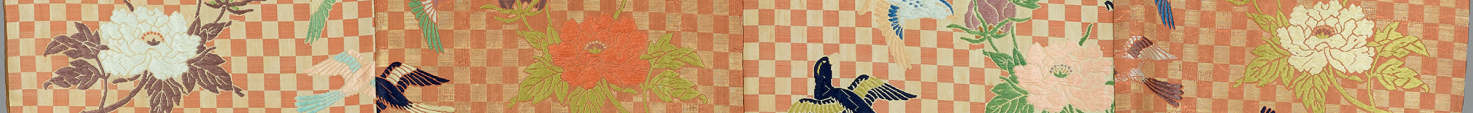

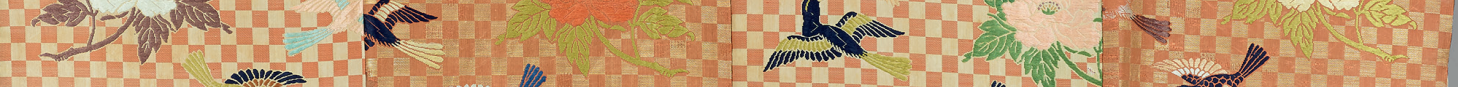
$\therefore$ ×.

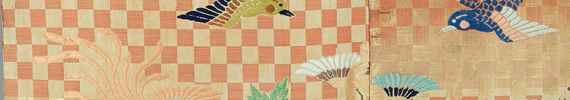

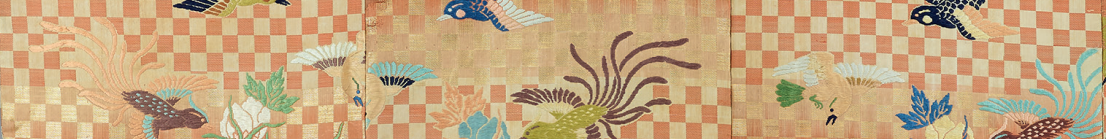

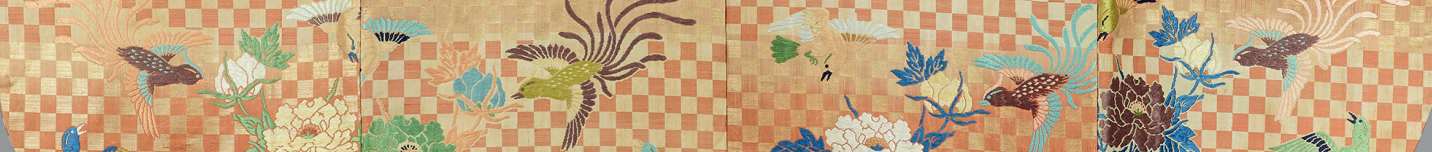

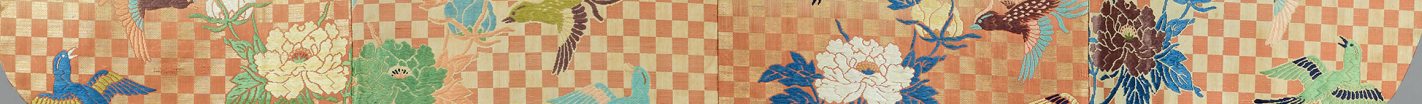
4 (2)

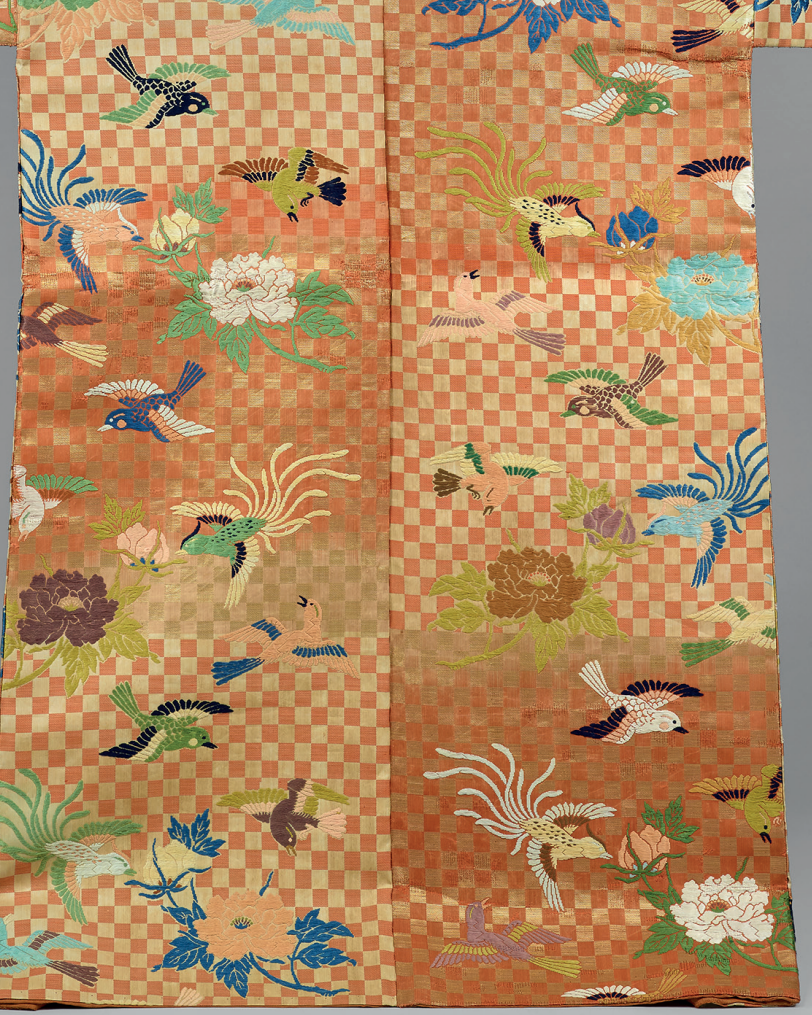


Cat. 6 Karaori met stokroos- en wilg-motieven, zijde, Japan, 1700-1800, Okura Museum of Art, inv.nr. some 12

In de $14^{\mathrm{e}}$ tot de $\mathrm{I}^{\mathrm{e}}$ eeuw, toen het no-theater langzaam vorm kreeg, was het gebruikelijk om kledingstukken samen te stellen uit een bonte schakering van contrasterende stukken stof. Dit was een manier om delen van oude, kostbare brokaten te hergebruiken en associatief om te gaan met motieven, om verrassende combinaties te vinden. Symmetrische, patchwork kimono's bleven ook vanaf de $\mathrm{I}^{\mathrm{e}}$ eeuw met het no-theater geassocieerd worden, ook toen de mode voor dagelijks gebruik ontwerpen gingen voorschrijven die zich asymmetrisch uitstrekten over het hele kledingstuk. In de karaori-weeftechniek (zie cat. 5) werd de patchworktraditie van de oude, sfeerrijke kostuums in ere gehouden. Voor dit exemplaar zijn voorafgaand aan het weven delen van de verticale scheringdraden in verschillende kleuren geverfd om blokken van kleurvlakken te krijgen. ${ }^{4}$ Omdat hier wat onregelmatigheid in zat, lopen de draden met de ene kleur wat over in het volgende kleurvlak erboven of onder. Daardoor hebben de kleurvlakken wat vloeiende randen. Ze geven het kostuum een zachtere, wat melancholische inslag die goed aansluit bij het gevoel van mysterie en ondoorgrondelijkheid dat no diende op te roepen. 


\section{3.}

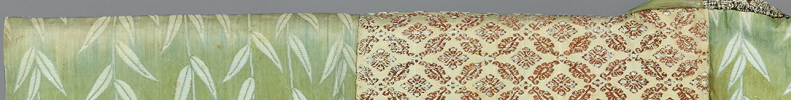
1
$N$

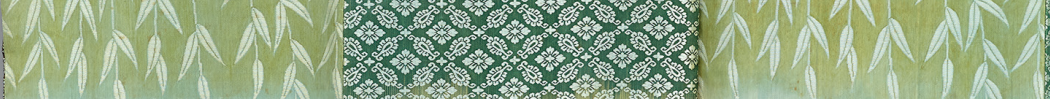

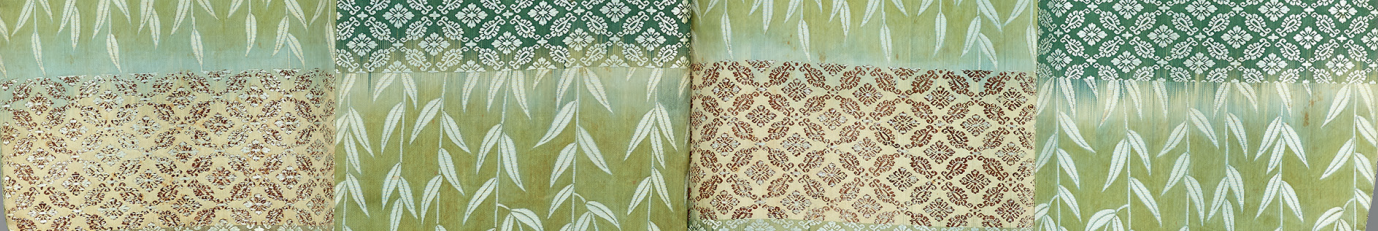
(2)

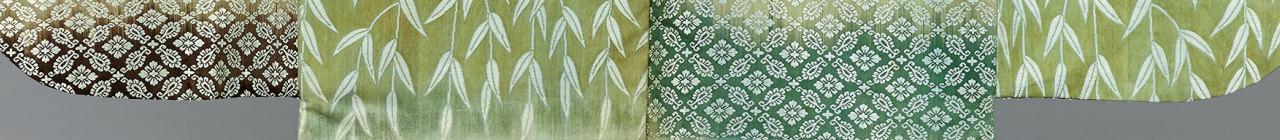

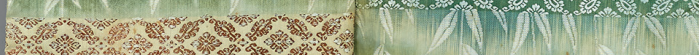

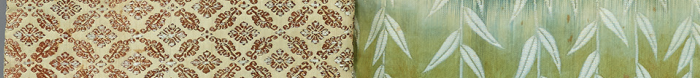
2.m.t.m. 2.3.

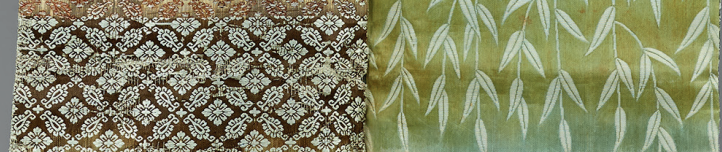
2.

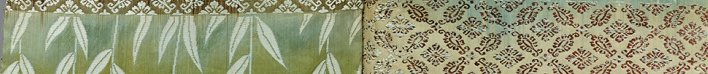

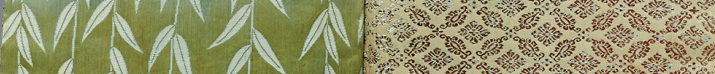
Nans (3) 

Cat. 7 Choken met heggen, waaiers en blauwe regen (Wisteria sinensis), zijde
en goudraad, Japan, 1700-1800, Okura Museum of Art, inv.nr. some 15

Er zijn verschillende soorten kortere jassen die bij het no-theater over de kleding worden gedragen. De choken is een ongevoerde jas van gaasgeweven stof die niet helemaal gestikt werd, zodat de panelen van het kledingstuk zich gracieus konden bewegen tijdens de dans. Doordat hier de zijde stof enigszins doorschijnend is, kan de onderliggende kleding er subtiel doorheen schijnen en de decoratie daarvan zich mengen met de bloemranken van de blauwe regen, elegant gedrapeerd over gouden waaiers. Op afbeelding 3 is een voorbeeld van een choken te zien.

De waaier is een passend motief voor een no-theater kledingstuk. Het is het hoofdattribuut van de acteur, dat op veel manieren kan worden gebruikt. Als tijdens het dansen met gebaren emoties worden aangegeven, kunnen die geaccentueerd worden met de waaier. Ook acties als slapen of luisteren worden met de waaier aangeduid, terwijl gesloten, half- of helemaal geopende waaiers kunnen dienen om een voorwerp te suggereren, zoals een mes, een lantaarn of de opkomende maan.

Afb. 3

Tsukioka Kogyo,

Danser in de rol van de kraanvogel in het stuk Tsurukame, detail schildering op zijde, Japan, begin $20^{\mathrm{e}}$ eeuw, collectie Josephine en Robert Schaap

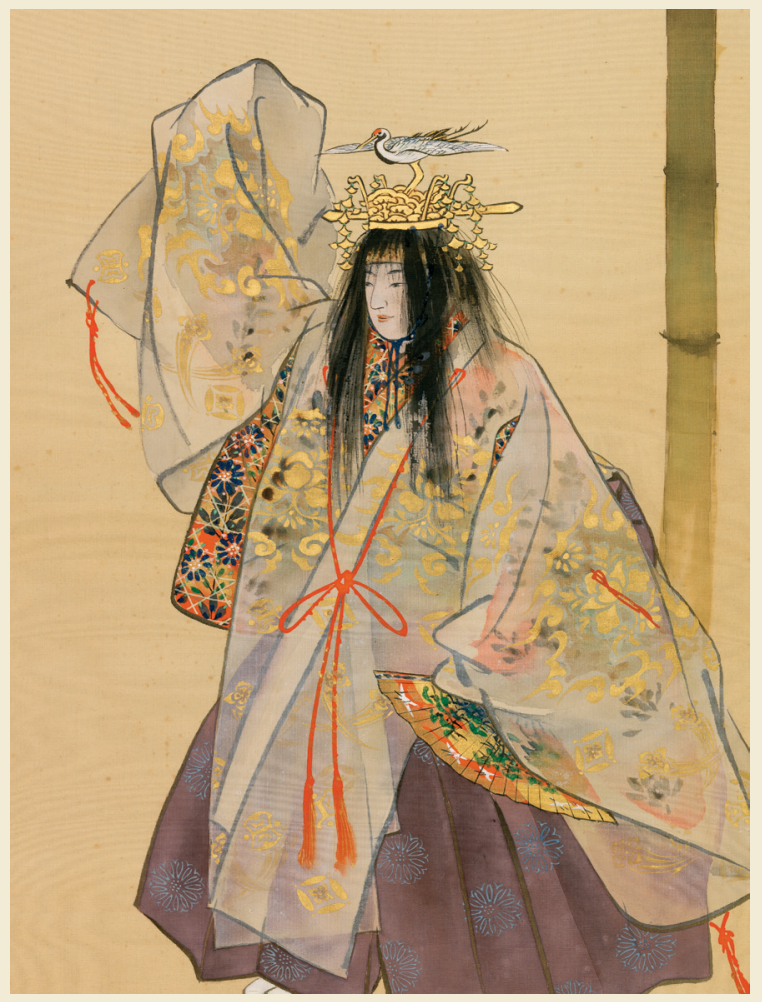




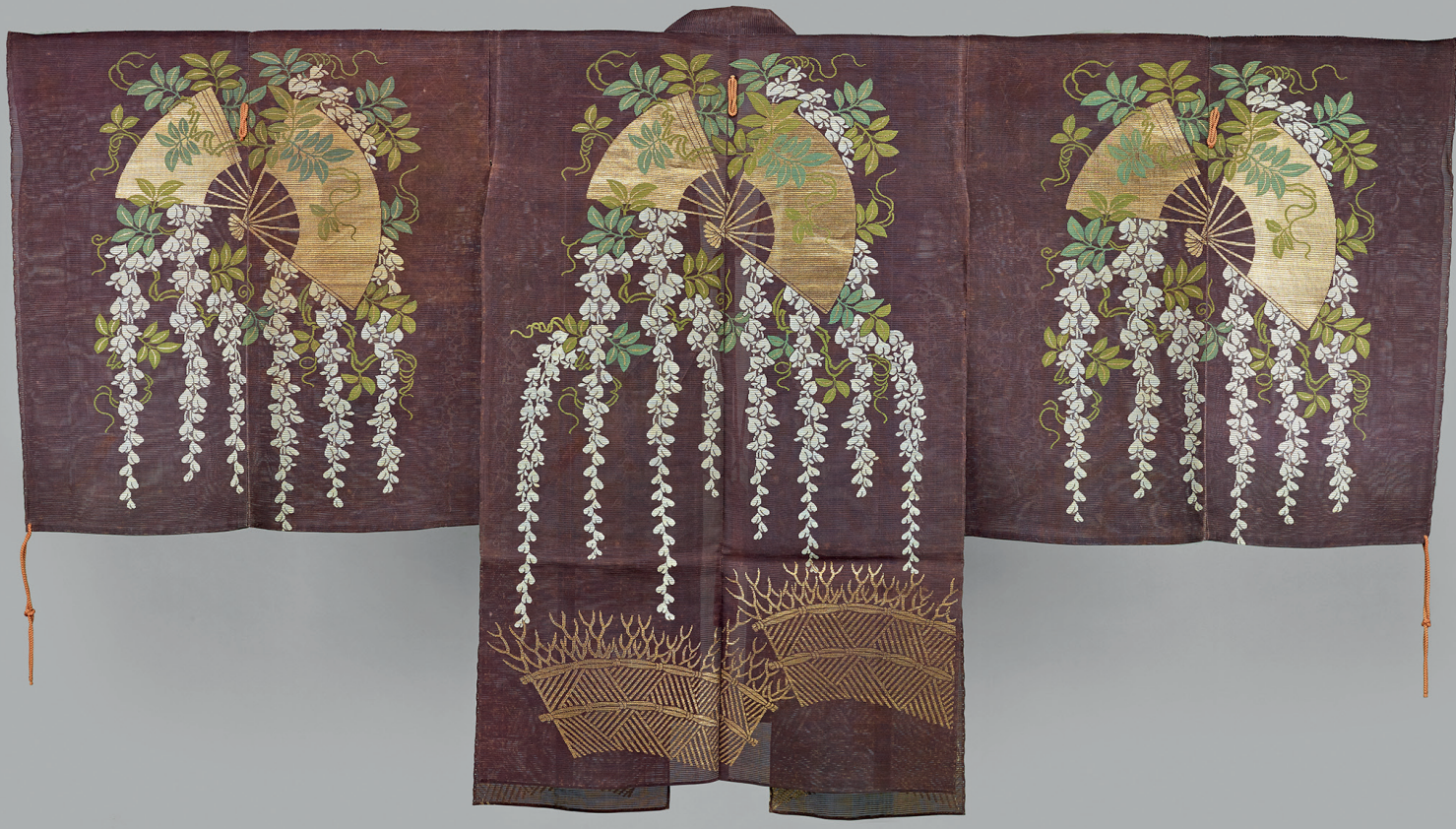


Christine M. Guth, Art, Tea, and Industry: Masuda Takashi and the Mitsui Circle, Princeton University Press, New Jersey, 1993.

Alan Kennedy, Japanese Costume: History and Tradition, Asam Biro, Parijs, 1990.

Erika de Poorter, No: Het klassieke theater van Japan, Amsterdam University Press, Amsterdam, 200I.

Okura Shukokan no meihin zuroku, Okura Museum of Art, Tokyo, 2003.

Okura Shukokan no meiho, tentoonstellingscatalogus Tenshin Memorial Museum of Art, Ibaraki, 2007.

Okura Shukokan no meihin, tentoonstellingscatalogus Yamanashi Prefectural Museum of Art, Kofu, 2012.

I Guth I993: 92.

2 De Poorter 20oI: 48-49.

3 Hierbij werden rond de versieringselementen omtreklijnen met rijstpasta aangebracht, waarna de motieven werden ingeschilderd. Als dat klaar was, werd de hele versiering met rijstpasta bedekt, waarna de stof in een verfbad ging om de achtergrondkleur te maken.

4 Bij deze ikat-techniek werd het deel van de draad dat niet gekleurd moest worden afgebonden, zodat de verf daar niet kon doordringen. 